\title{
Need for Aeromedical Evacuation High-Level Containment Transport Guidelines
}

\author{
Shawn G. Gibbs, Jocelyn J. Herstein, \\ Aurora B. Le, Elizabeth L. Beam, \\ Theodore J. Cieslak, James V. Lawler, \\ Joshua L. Santarpia, Terry L. Stentz, \\ Kelli R. Kopocis-Herstein, Chandran Achutan, \\ Gary W. Carter, John J. Lowe
}

Author affiliations: Indiana University School of Public Health, Bloomington, Indiana, USA (S.G. Gibbs, A.B. Le); University of Nebraska Medical Center College of Public Health, Omaha, Nebraska, USA (J.J. Herstein, T.J. Cieslak, C. Achutan, J.J. Lowe); University of Nebraska Medical Center College of Nursing, Omaha (E.L. Beam); University of Nebraska Medical Center College of Medicine, Omaha (J.V. Lawler, J.L. Santarpia); National Strategic Research Institute, Omaha (J.V. Lawler, J.L. Santarpia, G.W. Carter); University of Nebraska-Lincoln Charles W. Durham School of Architectural Engineering and Construction, Lincoln, Nebraska, USA (T.L. Stentz, K.R. Kopocis-Herstein)

DOI: https://doi.org/10.3201/eid2505.181948

Circumstances exist that call for the aeromedical evacuation high-level containment transport (AE-HLCT) of patients with highly hazardous communicable diseases. A small number of organizations maintain AE-HLCT capabilities, and little is publicly available regarding the practices. The time is ripe for the development of standards and consensus guidelines involving AE-HLCT.

$\mathrm{D}$ uring a highly hazardous communicable diseases (HHCD) outbreak, most patients are likely to be treated within the affected region. However, circumstances exist for which aeromedical evacuation high-level containment transport (AE-HLCT) of patients with HHCDs is necessary (e.g., political considerations, resource limitations, armed conflict). Although AE-HLCT has occurred since the 1970s, the 2013-2016 Ebola virus disease (EVD) outbreak in West Africa brought this practice to the forefront of public consciousness (1). During that outbreak, at least 33 patients with confirmed or suspected EVD were transported to EVD treatment facilities in the United States and Europe that were capable of high-level isolation. Asymptomatic persons with high-risk exposures (e.g., needle sticks, blood or body fluid splashes) have also been transported for quarantine. In 2016, two patients with Lassa fever were transported by AE-HLCT from Togo, 1 each to the
United States and Germany (2). Despite the introduction of an EVD vaccine, the Democratic Republic of the Congo is experiencing the second largest EVD outbreak in history; in December 2018, a US citizen exposed to EVD was transported to the University of Nebraska Medical Center for observation before being discharged in January 2019 (3). Clearly, AE-HLCT is an ongoing need.

The death rate from certain HHCDs can exceed $70 \%$, as was the case with EVD in parts of West Africa (4). Thus, streamlined policies and procedures for efficient, timely AE-HLCT can decrease transmission risk and optimize patient management in flight. Because of the significant risks to crews and receiving communities, HHCD patients must be managed by highly trained teams and organizations, especially considering the uncontrolled environment of AEHLCT missions and the potential for the rapid deterioration of patient condition. Historically, AE-HLCTs for HHCDs have been conducted by a limited number of military organizations or private corporations contracted by national governments or relief organizations to protect the wellbeing of their citizens or their volunteer personnel. Providers of AE-HLCT maintain teams of highly trained staff and regularly test, validate, and exercise their systems and procedures to ensure mission readiness. Moreover, these experienced organizations have recently developed systems with the capability of transporting multiple patients of varying levels of acuity during the same operation, expanding the capacity of AE-HLCT missions that historically had been limited to a single patient $(5,6)$.

Isolation of HHCD patients during aeromedical evacuation is a complex process with numerous requirements related to the preflight, in-flight, and postflight environments, involving highly knowledgeable and trained persons from a variety of professions, as well as specialized equipment and validated infection control processes (Table) (7). The safe and successful use of these AE-HLCT systems requires coordination and approval at all levels of government, as well as between governments, given that most AE-HLCT missions will cross international borders. Despite this complexity, no generally accepted standards exist outside the few organizations that have conducted them. Moreover, the processes, operations, and capabilities used, as well as the lessons learned from postmission evaluations, are not found in the peer-reviewed literature. Only a few case studies have been publicly disseminated because of security concerns, a desire to maintain proprietary information, or simply because of the niche field and limited audience. The literature is sparser still regarding the methods associated with the transportation of asymptomatic persons with high-risk exposures. Although we are aware that cooperation between these organizations often occurs, the lack of literature disseminated to the larger academic and practice community remains a problem. Without knowledge of the 
Table. Processes to be considered during an aeromedical evacuation high-level containment transport

\begin{tabular}{l}
\hline Environment, process to consider \\
\hline Preflight \\
Types of diseases \\
Decision to aeromedically evacuate \\
Training/drills \\
Regulations and legal limitation \\
Communication plan \\
Layout/space assessment \\
Other preparations \\
\hline In-flight \\
Personnel \\
Personal protective equipment \\
Type of isolation units \\
Procedures/capabilities inflight \\
Liquid and solid waste handling \\
Death in flight \\
Other contingency procedures \\
\hline Postflight \\
Decontamination \\
Equipment reuse \\
Waste disposal \\
Personnel monitoring
\end{tabular}

science that established these procedures or a broad continual review of such science, an inherent barrier persists for current or future researchers or practitioners attempting to build on ongoing research and experiences.

Finally, the limited amount of information about the processes, procedures, and equipment available from a small number of aeromedical organizations impedes scalability should the need arise. Most of the organizations that have historically conducted AE-HLCT missions often have limited capacity, personnel, or systems to conduct multiple missions, with most only able to conduct 1 or 2 AE-HLCT missions simultaneously. The lack of nonorganizational specific standards and specialization diminishes the ability to transfer such capabilities to other organizations that might have the desire and personnel to assist or to nations that currently lack such capabilities but might have a current or future need for such capabilities. A critical evaluation of the literature would enable the dissemination of lessons learned, thereby enhancing best practices and driving the field forward, ultimately leading to safer outcomes for patients, caregivers, and receiving communities. Because much of this information does not exist within peer-reviewed literature, much would be gained through a conference on the subject that evaluates various procedures and establishes consensus recommendations for best practices, including creation of a verified information exchange mechanism. The time is ripe for the development of standards and consensus guidelines involving AE-HLCT.

\section{About the Author \\ Dr. Gibbs is executive associate dean and professor of environmental health at Indiana University School of Public Health-Bloomington. His research interests include industrial hygiene and environmental exposure assessment, focusing on environmental microbiology and disrupting transmission of highly infectious diseases.}

\section{References}

1. Lotz E, Raffin H. Aeromedical evacuation using an aircraft transit isolator of a patient with Lassa fever. Aviat Space Environ Med. 2012;83:527-30. http://dx.doi.org/10.3357/ASEM.3094.2012

2. Woodruff Health Sciences Center. Experimental antiviral combo + immunology [cited 2019 Jan 15]. http://news.emory.edu/ stories/2017/06/lassa_kraft_mcelroy

3. Martinez G. American flown to Nebraska hospital after possible Ebola exposure in the Congo [cited 2019 Jan 15]. http://time.com/5490412/ebola-doctor-nebraska-medical-center

4. Uyeki TM, Mehta AK, Davey RT Jr, Liddell AM, Wolf T, Vetter P, et al.; Working Group of the U.S.-European Clinical Network on Clinical Management of Ebola Virus Disease Patients in the U.S. and Europe. Clinical management of Ebola virus disease in the United States and Europe. N Engl J Med. 2016;374:636-46. http://dx.doi.org/10.1056/NEJMoa1504874

5. Wade S. Scott Airmen train on transport isolation system [cited 2018 Apr 15]. http://www.af.mil/DesktopModules/ArticleCS/Print. aspx?Portalld $=1 \&$ ModuleId $=850 \&$ Article $=562739$

6. Phelps D. Ready for the challenge: Dobbins selected as home for new biocontainment system [cited 2018 Nov 8]. https://www.thefreelibrary.com/Ready+for+the+challenge $\% 3 \mathrm{~A}+$ Dobbins+selected + as + home + for + new + ...-a0435001746

7. Thoms WET, Wilson WT, Grimm K, Conger NG, Gonzales CG, DeDecker L, et al. Long-range transportation of Ebola-exposed patients: an evidence-based protocol. American Journal of Infectious Diseases and Microbiology. 2015;2(6A):19-24.

Address for correspondence: Jocelyn J. Herstein, College of Public Health, University of Nebraska Medical Center, 984388

Nebraska Medical Center, Omaha, NE 68198, USA; email:

jocelyn.herstein@unmc.edu

\section{Corrections}

\section{Vol. 24, No. 10}

A grant number was listed incorrectly in Human Pegivirus in Patients with Encephalitis of Unclear Etiology, Poland (I. Bukowska-Ośko et al.). The Polish National Science Center grant number should be 2017/25/B/NZ6/01463. The article has been corrected online (https://wwwnc.cdc.gov/eid/article/24/10/18-0161_article).

\section{Vol. 25, No. 2}

The number of cases of West Nile neuroinvasive disease was listed incorrectly in the abstract of Acute and Delayed Deaths after West Nile Virus Infection, Texas, USA, 2002-2012 (D.C.E. Philpott et al.). The article has been corrected online (https://wwwnc.cdc.gov/eid/article/25/2/18-1250_article). 